\title{
Peritoneal Lavage
}

National Cancer Institute

\section{Source}

National Cancer Institute. Peritoneal Lavage. NCI Thesaurus. Code C159340.

A minimally invasive procedure that permits sampling of peritoneal fluid for cytopathologic analysis. 